\title{
Inter-correlation of Green IT Computing Practices
}

\author{
Rodolfo S. Vargas, Ph.D. \\ Assistant Professor, Department of Project Management and Information Technology, College of Financial Sciences,
}

AMA International University-Bahrain, Salmabad, Kingdom of Bahrain

\begin{abstract}
This inter-correlation green IT computing highlights the significant factors that will affect the practices of stakeholders in the institution by means of adopting and implementing the practical techniques without spending too much resources in reducing the carbon emissions which are produced by the computer laboratories, servers and other devices connected to IT infrastructure used in the institutions.
\end{abstract}

Keywords: Adoption, Implementation, Green IT, Practices.

\section{INTRODUCTION}

Our mother earth now a days is changing, previously there are places around the globe not disturb any kind of natural disaster but now flooded even by simple monsoon rain. The devastation caused by different typhoons and intolerable level of snow were experienced by different countries as the major problems in this $21^{\text {st }}$ century. The natural disasters were triggered by the fast evolution of global computer network which is often representationally referred to as server. The overheads of energy to sprint the IT infrastructure are important factors of green computing. Almost two decades the cause of carbon emissions produced by electricity was associated to the green computing label.

The accumulations of greenhouse gases and enormous electricity consumption are the reasons for having climate change. The key in reducing greenhouse gases is to minimize electrical consumption while refining the routine of data centers and desktop computers. This center can produce lots of green-house gas emission by using wrong practices for IT. The stakeholders who have the concern with regard to this problem and can provide solution on their own initiatives and practices. These people should act individually and collectively to solve the issue of reducing the green-house gas emission.

The servers, workstations, monitors, data communication equipment such as routers and switches, and cooling systems comprise the computing environment. The electrical consumption of these components is constantly increasing. The increase in computer installation along with their frequent replacements has an impact to the environment. Stakeholders are under pressure in solving this problem

The key in reducing the greenhouse gases is one of the primary reasons of climate change to minimize electrical consumption [25]. The servers, computer laboratories and other devices connected to IT infrastructure produced lots of greenhouse gas emissions by using wrong practices for IT [25]. The stakeholders who have the concern with regard to this problem are the IT professionals, IT industry practitioners and IT users who can provide solutions [25].
These people should adopt and implement practical techniques individually and collectively to solve the issue of reducing the green house gas emissions [25].

"Positive relationship" and especially "Significant Relationship" are terms that can be used interchangeably with an emergent correlation of practices, adoption and implementation. Practical approaches are driving to reduce electricity consumption beyond just energy considerations. These practical approaches that are used to minimize the energy consumption will necessitate deep adoption on the practices which are anchored with the right implementation and which technique benefits of Green IT will be realized by the institution.

It defines inter-correlation as the outcome of certain patterns of relationships that occur together in a specified manner without suggesting that one causes the other to change. Therefore, as distinct, green computing practices notify the institution's sustainable IT in the near future and process assessment.

The objective of this paper is to assess the current literature on green IT computing and its significant relationship on green IT computing practices with the inspiration of identifying positive relationship among the three practical techniques and influence points to improve student significance, institutional significance and societal significance.

This study aims to determine the factors affecting the practices of stakeholders considering the adoption and implementation of the green IT computing as the drivers of good practices.

\section{RESEARCH METHODOLOGY}

This chapter explains the details on how the objectives of this study will be obtained. The methodology includes the research design, respondents, data collection, sampling procedure, instrument, and data analysis.

This study established the qualitative-descriptive analytical design. The outcomes of green IT will be analyzed to quality education and quality IT services. 
This study focus with the following questions:

1. What is the level of adoption of the stakeholders in Green IT Computing?

2. What is the level of implementation of the stakeholders in Green IT Computing?

3. Is there a significant relationship between the level of adoption and implementation of the stakeholders in Green IT Computing?

4. Is there a significant relationship between the level of practices and the level of adoption and implementation of the stakeholders in Green IT Computing?

Research Design

This study aims to bring the facts, conditions and experiences surrounding the pervasive spheres of computer peripherals used in the university. The data and information gathered were recorded, described, analyzed and interpreted in their normal occurrence or as they really exist. It is the context that the researcher made use of the descriptive method. The descriptive method is aimed at discovering the item relationship among variables of a problem, describing them by determining the cause and effect of the relationship.

Participants of the Study

A total of 46 stakeholders from the College of Computer Studies consist of AMAIUB Officers, IT Manager, Head of the Facilities, Head of CS department, and Faculty Members in the College of Computer Studies were utilized in this study because CCS is the prime mover for any IT enhancement and development and its faculty members are already acquainted with various trends and developments.

Sampling Procedure

The data and information gathered from the stakeholders served as the basis on the findings of the study. The researchers will use the convenience sampling techniques

Research Instruments

There were two instruments used in this study. These are questionnaire and unstructured interview.

\section{A. Questionnaire.}

A survey questionnaire was formulated, centered on the assessment of the respondents on the green IT.

B. Unstructured Interview

To clarify the respondents answer to the survey questionnaire distributed to them and to check the authenticity of the responses, the researcher conducted the on-the-spot interview with the respondents who have much concern on the implementation of green IT.

Data Gathering Procedures

The researcher utilized actual data provided by the stakeholders. Data gathering procedures follow these three phases: administration of the questionnaire [4], interview and collection of data, tabulation and analysis of data.

Statistical Treatment of Data

In the analysis of data the following statistical tools and techniques were used:

1. Percentage - This is a measure of central tendency

which describes a part in relation to the whole of this study.

2. Mean - This is used to determine the result of the conducted questionnaire on green IT. The items means are interpreted using the Rating Scale Method as indicated below. The criteria being used is served as the basis for the interpretation of the results from the concept of boundary of numerals as arbitrarily made as follows:

Mean Value

$3.26-4.00$

$2.51-3.25$

$1.76-2.50$

$1.00-1.75$

Mean Value

$3.26-4.00$

$2.51-3.25$

$1.76-2.50$

$1.00-1.75$

Mean Value

$3.26-4.00$

$2.51-3.25$

$1.76-2.50$

$1.00-1.75$

3. To determine if there is relationship between the following pair of variables, the Pearson (r) product moment correlation was used to test correlation between:

Practice (x) - Adoption (y)

Practice ( $\mathrm{x}$ ) - Implementation (y)

Implementation ( $\mathrm{x}$ ) - Adoption (y)

The following formula was applied:

$\mathrm{r}=\mathrm{N} \Sigma \mathrm{XY}-(\Sigma \mathrm{X})(\Sigma \mathrm{Y})$

$\sqrt{\left[\mathrm{N} \Sigma \mathrm{X}^{2}-(\Sigma \mathrm{X})^{2}\right]\left[\mathrm{N} \Sigma \mathrm{X}^{2}-(\Sigma \mathrm{Y})^{2}\right]}$

Where:

$\mathrm{r}=$ pearson $\mathrm{r}$ correlation coefficient

$\Sigma x y=$ the sum of cross product, $x y$.

$\Sigma \mathrm{x}=$ the sum of numbers belonging to $\mathrm{x}$.

$\Sigma \mathrm{x}^{2}=$ the sum of the squared numbers belonging of $\mathrm{x}$.

$\Sigma y^{2}=$ the sum of the squared numbers belonging of $y$.

$(\Sigma \mathrm{x})^{2}=$ the squared numbers belonging of $\mathrm{x}$.

$(\Sigma y)^{2}=$ the squared numbers belonging of $\mathrm{y}$.

The interpretation for range of " $r$ " in terms of verbal description according to Pagoso is shown below.

0.0 - no correlation

$0.01-0.2$ - negligible correlation

$0.21-0.40$ - low correlation

0.41 - 0.60 - moderate correlation

$0.61-0.80$ - substantial correlation

081 - 0.90 -high correlation

$0.91-0.99$ - very high correlation

\section{RESEARCH PLAN}

The correlation will be used for two reasons: One is to establish the association of the three variables to attest whether the theories of these variables are supported by the data. The other reason is to describe in quantitative terms the extent to which the scanning variables were related to one another; both to test the hypothesis. 
The research will be organized based on the following:

- Determine the level of practices, adoption and implementation of the green IT computing

- Analyze and interpret the Inter-correlation of each of the variables.

- Recommend the factors that affect the practices

\section{RESULTS AND DISCUSSION}

This chapter presents the analysis and interpretation of data gathered through the use of level of practices, adoption and implementation of stakeholders. Findings were presented in tabular forms and discussions were organized based on the statement of the problem posed in Chapter 1 .

Summary of Mean, Frequency and Percentage Distribution of Factors Affecting Green IT

\begin{tabular}{|l|c|c|c|c|}
\hline \multicolumn{1}{|c|}{ Factor } & Mean & $\begin{array}{c}\text { Verbal } \\
\text { Interpreta } \\
\text {-tion }\end{array}$ & $\begin{array}{c}\text { Frequ } \\
\text {-ency }\end{array}$ & $\begin{array}{c}\text { Percen } \\
\text {-tage } \\
(\%)\end{array}$ \\
\hline Practices of & $\mathbf{2 . 4 3}$ & Fair & 3 & 13.04 \\
the stake & & & 11 & $\mathbf{4 7 . 8 3}$ \\
holders of & & & 5 & 21.74 \\
Green IT (29) & & & 4 & 17.39 \\
\hline Adoption of & $\mathbf{2 . 4 8}$ & Slightly & 4 & 17.39 \\
the stake & & Adopted & 9 & $\mathbf{3 9 . 1 3}$ \\
holders of & & & 4 & 17.39 \\
Green IT (31) & & & 6 & 26.09 \\
\hline Implementatio & $\mathbf{2 . 5 2}$ & Moderat & 4 & 17.39 \\
n of the stake & & -ely & 9 & $\mathbf{3 9 . 1 3}$ \\
holders of & & Impleme & 5 & 21.74 \\
Green IT (32) & & nted & 5 & 21.74 \\
\hline
\end{tabular}

(29) Level of the Practices of Stakeholders in Green IT The level of practices of the majority of the stakeholders in Green IT of the university is fair as shown by the mean of 2.43. The Percentage of 17.39 is equivalent to 4 out of $23 ; 21.74$ percent $(21.74 \%)$ is equivalent to 5 out of 23 ; 47.83 percent $(47.83 \%)$ is equivalent to 11 out of 23 and 13.04 percent $(13.04 \%)$ is equivalent to 4 out of 23 . This means that majority of the stakeholders perceived that "behavioral changes of stakeholders can achieve Green IT in the institution more than the technical Green IT solutions".

Table above clearly shows that practices of stakeholders is fair. This would mean that the stakeholders of the institution are practicing Green IT computing. The stakeholders believe that Green IT will improve the process and quality of works in the institution but they have reservations on their acts toward green IT computing practices. The stakeholders need to be guided by means of providing a clear vision to be accomplished on the direction of the green IT computing.

(31) Level of the Adoption of Stakeholders in Green IT The level of adoption of the majority of the stakeholders in Green IT of the university is slightly adopted as shown by the mean of 2.48. The percentage of 26.09 percent $(26.09 \%)$ is equivalent to 6 out of $23 ; 17.39$ percent
$(17.39 \%)$ is equivalent to 4 out of $23 ; 39.13$ percent (39.13) is equivalent to 9 out of 23 and 17.39 percent $(17.39 \%)$ is equivalent to 4 out 23 . The majority of the stakeholders agreed that by adopting the Green IT, the efficiency and effectiveness of the institution on the value system which is associated with motivation and norm will be improved.

The number 31 on the above table shows that the majority of the stakeholders slightly adopted the factor on the effect of Green IT computing on their usual used and unused of computer devices in the institution. This would mean that the institution is actively engaged and has initiated Green IT computing measures with the corresponding documents but no indication of its progress. It further shows that no incentives were given to those stakeholders who were practicing and adopting the Green IT in the institution.

(32) Level of the Implementation of Stakeholders in Green IT

The level of Implementation of stakeholders in Green IT is moderately implemented as shown by the mean of 2.52 . The percentage of 21.74 is equivalent to 5 out of $23 ; 21.74$ percent or $(21.74 \%)$ is equivalent to 5 out of $23 ; 39.13$ percent or $(39.13 \%)$ is equivalent to 9 out of 23 and 17.39 percent or $(17.39 \%)$ is equivalent to 4 out of 23 .This means that the majority of the stakeholders is moderately implemented on the effect of carbon emissions disposed by the computer peripherals.

The number $\mathbf{3 2}$ on the table shows that the majority of the stakeholders are moderately implementing the green IT. This would mean that the implementation of the the green IT computing in the Institution leads to shorter processes, achieves a better utilization of existing equipment and extends the life-span of currently utilized equipment.

\section{Correlation of Respondent Level of Practice in Green} IT

The relationship between the level of Practices of the stakeholders and the selected variables was obtained using the Pearson Product moment of correlation.

Table 2 Summary of Coefficient of Correlation of the Variables

\begin{tabular}{|l|c|c|}
\hline Discipline & $\begin{array}{c}\text { Coefficient of } \\
\text { Correlation }(r)\end{array}$ & Interpretation \\
\hline P and A(1) & $\mathbf{. 0 1 0}$ & Negligible correlation \\
\hline P and I (2) & $\mathbf{. 0 1 0}$ & Negligible correlation \\
\hline I and A (3) & $\mathbf{. 9 4 1}$ & Very high correlation \\
\hline
\end{tabular}

(1) Practices and Adoption in Green IT

Table 2 shows the correlation between Practice and Adoption. This means that the computed value of .010 indicates a little significant relationship between the level of adoption and their level of practices. There is a negligible correlation between Practices and Adoption.

(2) Practices and Implementation in Green IT

As tabulated in table 2, it was found out that the correlation of .010 shows negligible relationship between practices and Implementation. Implementation has a small 
effect on the level of practices. This means that the stakeholders are religiously interested and have patience in following the initiatives of the institution in the Green IT computing thus, the Green IT practices and implementation help the society in general.

(3) Implementation and Adoption in Green IT

Table 2 shows the correlation between Adoption and Implementation. The computed value is .941 which means very high correlation. This proves that there is significant relationship between the level of adoption and level of implementation. Implementation and adoption are influencing each other. Adoption affects implementation and vice versa.

\section{CONCLUSION}

The study analyzed the level of adoption, implementation and practices of stakeholder's in the university settings. The purpose of this study is to determine the relationship affecting the practices of the stakeholders in reducing the carbon emission in the university.

\section{FINDINGS}

The study revealed the following findings:

1. The level of adoption of stakeholders is :

\section{a) Adoption}

The level of adoption of the majority of the stakeholders in Green IT of the institution is slightly adopted as shown by the mean of 2.48. The percentage of 26.09 percent $(26.09 \%)$ is equivalent to 6 out of $23 ; 17.39$ percent $(17.39 \%)$ is equivalent to 4 out of $23 ; 39.13$ percent (39.13) is equivalent to 9 out of 23 and 17.39 percent $(17.39 \%)$ is equivalent to 4 out 23 . The majority of the stakeholders agreed that by adopting the Green IT, the efficiency and effectiveness of the institution on the value system which is associated with motivation and norm will be improved.

\section{The level of implementation of stakeholders is:}

\section{b) Implementation}

The level of Implementation of stakeholders in Green IT is moderately implemented as shown by the mean of 2.52 . The percentage of 21.74 is equivalent to 5 out of $23 ; 21.74$ percent or $(21.74 \%)$ is equivalent to 5 out of $23 ; 39.13$ percent or $(39.13 \%)$ is equivalent to 9 out of 23 and 17.39 percent or $(17.39 \%)$ is equivalent to 4 out of 23 .This means that the majority of the stakeholders is moderately implemented on the effect of carbon emissions disposed by the computer peripherals.

3. Is there a significant relationship between the level of adoption and implementation of the stakeholders in Green IT Computing?

The computed value is .941 which means very high correlation. This proves that there is significant relationship between the level of adoption and level of implementation. Implementation and adoption are influencing each other. Adoption affects implementation and vice versa.
4. Is there a significant relationship between the level of practices and the level of adoption and implementation of the stakeholders in Green IT Computing?

a) Practices and Adoption

This means that the computed value of .010 indicates a little significant relationship between the level of adoption and their level of practices. There is a negligible correlation between Practices and Adoption.

b) Practices and Implementation

It was found out that the correlation of .010 shows negligible relationship between practices and Implementation. Implementation has a small effect on the level of practices. This means that the stakeholders are religiously interested and have patience in following the initiatives of the institution in the Green IT computing thus, the Green IT practices and implementation help the society in general.

On the basis of the foregoing results and in the light of the conditions under which the study was undertaken, it is concluded that:

1. Adoption and Implementation affect the practices but with a small varying factor. This means that regardless of how the stakeholders adopt and know how to implement the Green IT in the institution, it does not affect the stakeholders practices.

2. The significant factor which contributed to the practices of stakeholders is the correlation of adoption and implementation. By adopting and implementing Green IT, it improves the efficiency and effectiveness of the institution due to their embedded value system with motivations and norms as guides in order to influence the stakeholders to implement the Green IT.

\section{REFERENCES}

[1] "Methods, Metrics and motivation for Green Computer Science Program", Mujtaba Talebi and Thomas Way, 2009

[2] "Managerial Attitudes Towards Green IT: An Explorative Study of Policy Drivers", Pradipta Sarkar and Leslie Young, PACIS 2009 Proceedings

[3] "Green IT Best Practices at the University of Michigan", MaryBeth Stuenkel, EDUCAUSE Quarterly, 2009

[4] "A Techno-Economic Perspective of Green IT Implementation in Europe and the US", Alberto O. et..al, 2011

[5] "GREEN IT ADOPTION: A MOTIVATIONAL PERSPECTIVE", Alemayehu Molla and Ahmad Abareshi

[4] "ROADMAP TO A GREEN CAMPUS", U.S. Green Building Council, 2101 L Street NW Suite 500 Washington, D.C. 20037, 2010

[5] "Sustainable IT Services: Assessing the Impact of Green Computing Practices", Robert R. Harmon

[6] "Harnessing Green IT: Principles and Practices", San Murugesan, 2008

[7] "Green IT: The New Industry Shock Wave", S. Mingay, Gartner RAS Research Note G00153703, 2007

[8] "E-readiness to G-Readiness: Developing a Green Information Technology Readiness Framework", Molla A. et..al, $19^{\text {th }}$ Australian Conference on Information Systems, Christchurch, 2008

[9] "Green IT: Why Mid-size Companies Are Investing Now", Infotech Research Group, Technical Report, Toronto, Canada, July 2010

10] "A Green ICT Framework: Understanding and measuring Green ICT”, CR Connection Research, Technical Report, Australia, May 2010

[11] "Green Computing: Reducing Energy Cost and Carbon Footprint of Information Processing Systems", Massoud Pedram, ACM Journal on Issues on Information Technology, Vol. 8, No. 4, Los Angeles, California, 2009 
[12] "University of Pennsylvania Carbon Footprint", Penn Praxis, Technical Report, University of Pennsylvania, October 2007

[13] "Implementing Green IT: Eleven ways I.T. Can Lower Power Consumption, Reduce Costs and Eliminate Waste", CDW-G White Paper, http://www.cdwg.com

[14] "Adelphi University: Implementing a Holistic Green IT Strategy to Create Institutional Engagement", Bob Albreacht and Judith A. Pirani, ECAR Case Study 2, 2010

[15] "Developing and Justifying Energy Conservation Measures: Green IT under Construction", Jacqueline Cobett, et..al, AMCIS 2010 procedings

[16] "Green IT Report Regional Data - United States and Canada", Survey Results, Symantec, May 2009

[17] "The Green Data Center- a Symantec Green IT Guide", Symantec Corporation, 2008

[18] "A REPORT ON SUSTAINABLE IT IN THE USA, UK, AUSTRALIA AND INDIA", Connection Research Services Pty Ltd, 2010

[19] "The True Value of Green IT-An EMA Research Report", An Enterprise Management Associates (Ema) Research Report, 2008

[20] "Green/Sustainable IT/IS: Concepts and Cases", Laura B. Iacobelli, et..al, AMCIS 2010 proceedings

[21] "Carbon Footprint of a Typical Business Desktop From Dell", Markus Stutz, EMEA Environmental Affairs Manager, October 2010

[22] "Level of Congruency of Perceived and Projected Corporate Image of Selected Catholic Higher Educational Institution.”, Lacerna, Antoniette Z. (2006) Unpublished Dissertation, Colegio de San Juan de Letran, Manila

[23] "Introduction to statistics", Pagoso, Cristobal et..Al, 1985, Rex Printing Press, Quezon City

[24] "Towards a Framework for Decision Making Regarding IT Adoption", Osden Jokonya, Jan H. Kroeze, and John A. van der Poll.

[25] "GREEN IT MODEL: ITS'S IMPLICATIONS TO IT INFRASTRUCRURE", Rodolfo S. Vargas, AMAIUB-CCS RESEARCH JOURNAL, Volume 2, Issue 1, September 2012 